\title{
AC 2010-1045: AN INFRASTRUCTURE TO FACILITATE THE CREATION OF COURSES ON TECHNOLOGY AND ENGINEERING FOR NON-ENGINEERS.
}

\section{John Krupczak, Hope College}

Senior Fellow, Center for the Advancement of Scholarship on Engineering Education

(CASEE)National Academy of Engineering and Professor of Engineering, Hope College

Timothy Simpson, Pennsylvania State University

Professor of Mechanical and Industrial Engineering and Engineering Design and Director, The Learning Factory, Pennsylvania State University

Vince Bertsch, Santa Rosa Junior College

Professor of Engineering and Physics

Kate Disney, Mission College

Engineering Instructor

Elsa Garmire, Dartmouth College

Member, National Academy of Engineering and Sydney E. Junkins 1887 Professor of Engineering, Dartmouth College

Seung Ki Moon, Pennsylvania State University

Research Associate, Department of Mechanical Engineering and Industrial \& Manufacturing Engineering 


\title{
An Infrastructure to Facilitate the Creation of Courses on Technology and Engineering for Non-Engineers
}

\begin{abstract}
Technology is foundational to our current way of life, and informed citizens need an understanding of what technology is, how it works, how it is created, how it shapes society, and how society influences technological development. According to the National Academy of Engineering (NAE), all Americans need to better understand the wide variety of technology used every day. In "Technically Speaking: Why All Americans Need to Know More about Technology" (2002), and "Tech Tally: Approaches to Assessing Technological Literacy" (2006), the NAE has outlined the characteristics of a technologically literate citizen. Some engineering educators are beginning to take an interest in offering courses on engineering and technology for non-engineers. However an obstacle to offering courses for non-engineers is a lack of relevant course materials for both students and instructors. In addition, varying interpretations of what non-engineers should learn about technology can result in widely different course curricula and student learning outcomes. To address these two issues, an online course development site is being established. Development is based on four course models that address NAE recommendations in a consistent manner. These four types of courses are (1) technology survey courses that provide a broad overview of technological topics, (2) technological focus courses that address a more specific area such as the hydrogen economy or energy, (3) courses that emphasize the engineering design process, and (4) technology connections courses that explore the connections between technology and other areas of society and culture. The online resource will allow engineering faculty to obtain materials from the database of existing resources.
\end{abstract}

\section{Introduction}

It is widely recognized that our standard of living depends, in large part, on the application of technology. Recently the National Academy of Engineering (NAE) has advocated that citizens need an understanding of what technology is, how it works, how it is created, how it shapes society, and how society influences technological development ${ }^{1,2}$. In addition, the International Technology Education Association (ITEA) and the American Association for the Advancement of Science (AAAS) have also developed standards defining technological literacy. 3,4

A recent NSF-sponsored workshop at the National Academy of Engineering (NAE), attempted to identify standard models for teaching technological literacy courses. ${ }^{5}$ As an outcome of that workshop, a framework was developed for evaluating courses on engineering and technology for non-engineering students. The framework also establishes a context for discussing standard models for these courses. The proposed framework will assist faculty in adapting existing innovative course materials into their 
own courses and provide guidance in developing courses that are consistent with the NAE recommendations.

\section{Description of Framework}

The framework for development of general education engineering course development is shown in Figure 1. The framework is in the form of a matrix that maps content areas in the vertical direction and specific topics areas in the horizontal direction. The framework merges the NAE and ITEA standards. The topic areas are taken from the "Designed World" categories defined by the ITEA 2000 Standards $^{3}$. The rows are specific crosscutting concepts under the broader headings of Systems, Design, and Connections, which are based on the four content areas defined by the NAE in Tech Tally ${ }^{2}$.

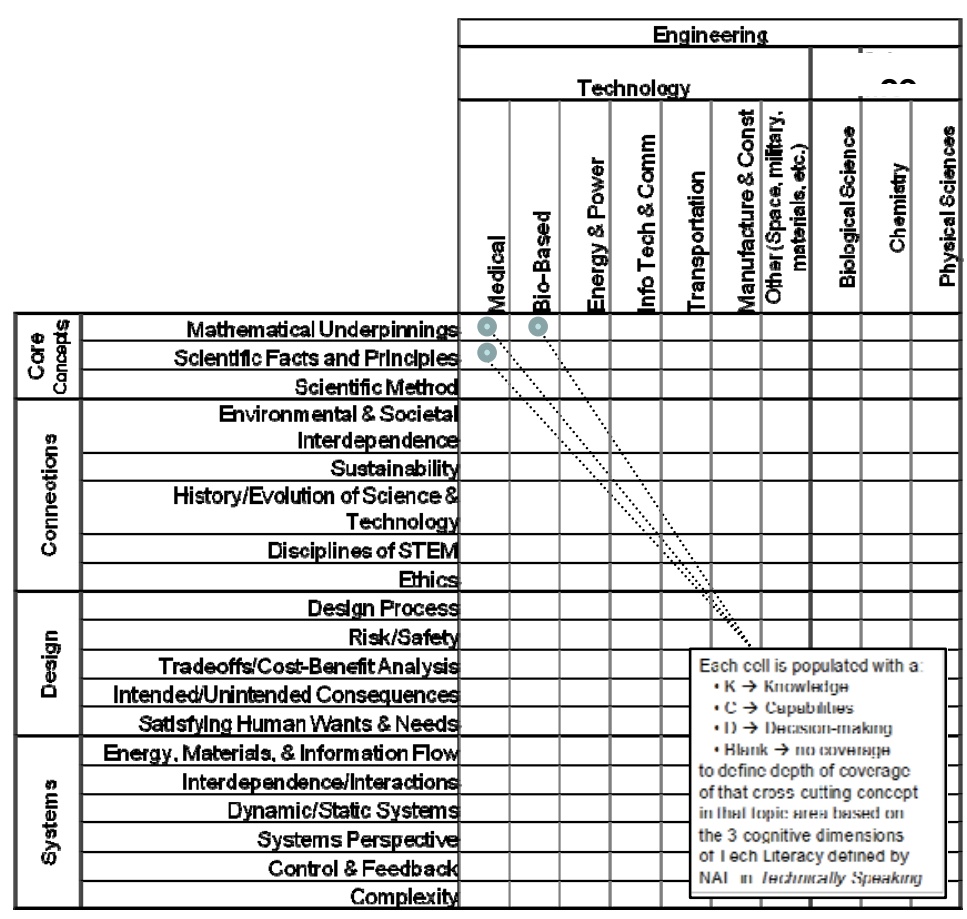

Figure 1: Technological Literacy Course Evaluation Matrix

For each cell in the matrix, the level or depth of coverage in each area can be indicated. The depth of coverage of that topic area is based on the three Cognitive Dimensions of Technology Literacy that are defined in Technically Speaking ${ }^{1}$ and Tech Tally ${ }^{2}$ :

- $\mathrm{K} \rightarrow$ Knowledge: the course will provide knowledge about this concept.

- $\mathrm{C} \rightarrow$ Capabilities: the course will develop capabilities in this cross-cutting concept that can be applied within the context of this technology topic area.

- $\quad \mathrm{D} \rightarrow$ Decision-making: the course will enable decision-making within the context of this cross-cutting area 
A review of existing courses on technological literacy identified four common course types. ${ }^{4,5}$ These are:
(1) Technology Survey Courses
(2) Technology Focus Courses
(3) Technology Design Courses
(4) Technology Critique, Assess, Reflect, Connect Courses

These four models emerged from efforts to discern patterns that may exist in the courses that have already been developed by engineers for non-engineering students. The technology survey courses offer a broad overview of a number of areas of engineering and technology. The technology topics or focus course is narrower in scope and develops one well-defined area. Examples of focus courses might be Nanotechnology, Energy, or Information Technology. The engineering design course, or technology creation, places an emphasis on the engineering design process as it is used to develop technological solutions to problems. The last model to emerge is concerned with assessing technological impacts, connecting technological developments to other areas of society, history and culture, or reflecting on engineering in a broader context.

These standard models can be incorporated into the framework as shown in Figure 2. The highlighted areas indicate the approximate range of topics for each type of course.

\section{Project Goals and Objectives}

This work will develop a framework for developing and evaluating courses on engineering and technology for non-engineers. The objectives for this project are to:

- Refine and validate the proposed framework for evaluating general education engineering courses.

- Pilot test the framework through development of pilot courses.

- Establish the foundation for a repository of engineering for general education and technological literacy course materials based on this framework.

The framework shown in Figures 1 and 2 will serve as an organizational infrastructure for a web-based repository of shared course materials. The long-range goal of this work is to use this framework as a portal for obtaining publicly available materials on technological literacy courses for non-engineers. Instructors can access materials and develop curriculum for new courses in technological literacy by reviewing existing courses and resources. The goal is to reduce the time and effort needed by faculty to develop courses that fit the educational needs of a variety of students. 


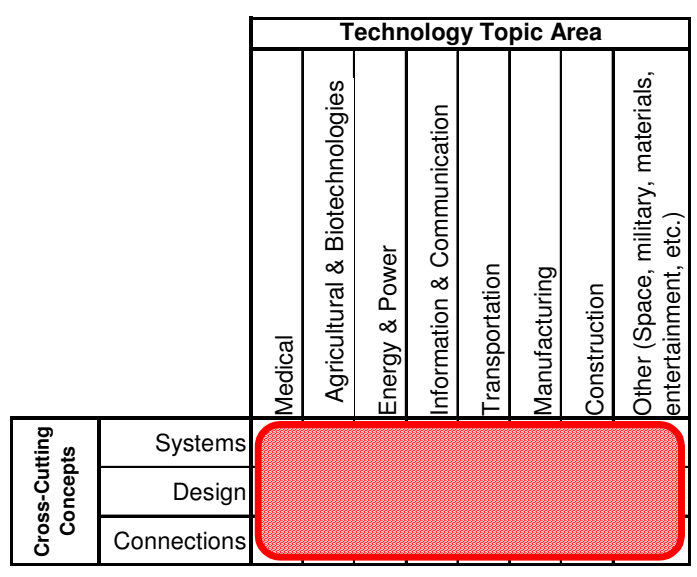

(a) Technology Survey Courses

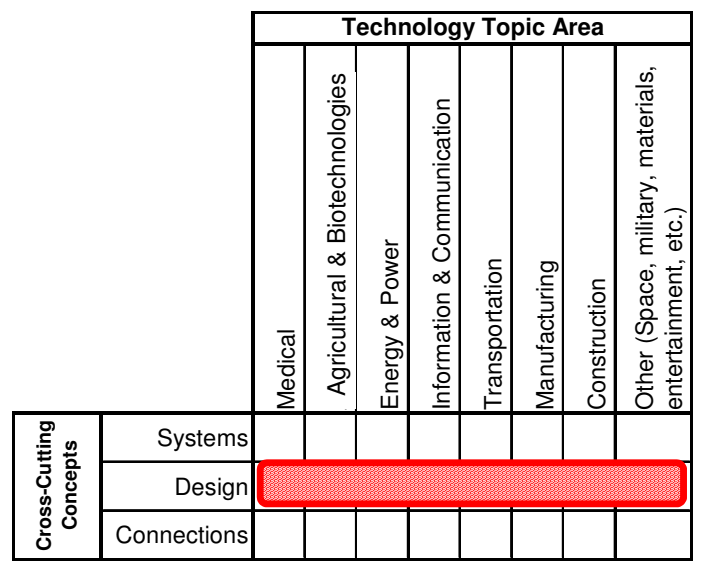

(c) Technology Design Courses

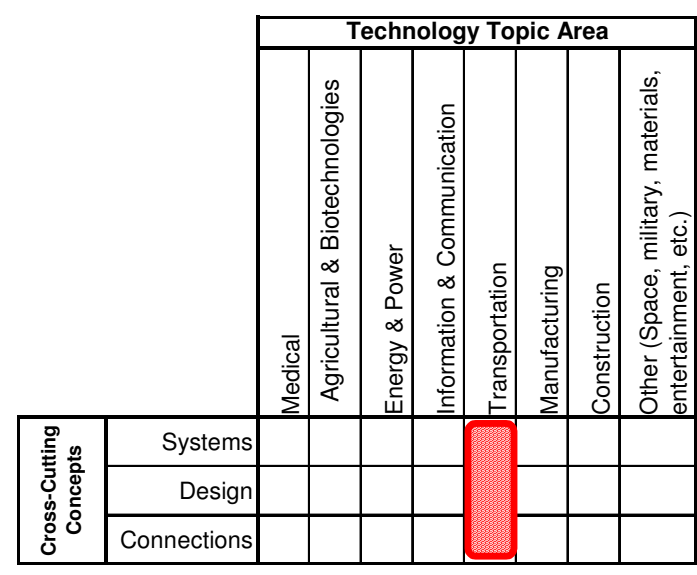

(b) Technology Focus Courses

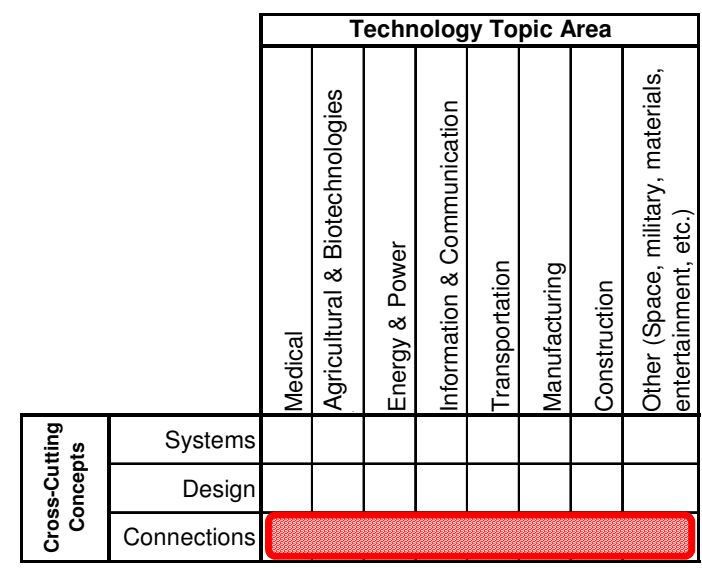

(d) Technology Critique/Assess/Reflect/Connect Courses

Figure 2: Matrix used to define four types of Technological Literacy courses

\section{Acknowledgment}

This work was supported by the National Science Foundation under awards: DUE0736615 and DUE-0714137. Any opinions, findings, and conclusions or recommendations expressed in this material are those of the authors and do not necessarily reflect the views of the National Science Foundation. Mary Annette Rose and Barbara Oakley contributed essential help in developing this framework.

\section{Bibliography}

1. Pearson G., and A.T. Young, editors, Technically speaking: Why all Americans need to know more about technology, National Academies Press, (2002). 
2. Garmire, E., and G. Pearson, editors, Tech Tally: Approaches to Assessing Technological Literacy, editors, National Academies Press, (2002).

3. International Technology Education Association. Standards for Technological Literacy, International Technology Education Association, Reston, VA (2000).

4. Project 2061: Benchmarks for Science Literacy, American Association for the Advancement of Science, Oxford University Press, (1993).

5. Krupczak, J.J., D. Ollis, W. B. Carlson, K.Neeley, R. Pimmel, and G. Pearson, "The Technological Literacy of Undergraduates: Developing Standard Models," Proceedings of the 37th ASEE/IEEE Frontiers in Education Conference (2007).

6. Krupczak, J.J., D. Ollis, "Technology Courses for Undergraduates: Developing Standard Models," Proceedings of the American Society for Engineering Education Annual Conference, June 22 - 25, 2008, Pittsburgh, PA. 